\title{
Iron chelation in haematomas at fracture sites
}

\author{
M. C. O'SHAUGHNESSY, GILliAN M. BRUNSTRÖM, AND J. FIELDING \\ From Paddington General Hospital, London
}

SYNOPSIS Previous work suggested that during the catabolism of haemoglobin a physico-chemical form of iron was released which was more readily chelatable by desferrioxamine than normal storage forms, as ferritin-haemosiderin. Desferrioxamine chelation was therefore investigated in five patients with major fractures in which haemoglobin catabolism is greatly enhanced by the red cell destruction which proceeds in the associated haematoma. Considerable increases in the amounts of iron mobife ized by desferrioxamine were observed from the second day after injury. In severe interstitial haemorrhage, these values tended to increase until 10 to 20 days, and sometimes were as high as chelation values seen in haemochromatosis. These results are considered to support the hypothes $B$ that a highly chelatable form of iron is found at some stage during haemoglobin catabolism.

During a study of the iron-chelating agent desferrioxamine, a method of measuring the amount of body iron chelated by a standard intravenous bodyweight dose of desferrioxamine was devised (Fielding, 1965). To establish the validity of the technique as a measure of body iron stores, clinical conditions were investigated in which body iron status could reasonably be deduced from other data. Storage iron as ferritin-haemosiderin was shown to be a major source of body iron chelated by desferrioxamine, and high, normal and low body iron status were differentiated. An unexpected finding was the relatively large amounts of body iron chelation which occur in pathological states associated with haemolytic processes. Evidence was adduced to suggest that the source of this iron was not the moderate increase in iron stores usually associated with haemolytic anaemias, but that it was iron newly released from its porphyrin bond during haemoglobin catabolism. Quantitative considerations showed that similar amounts of iron were chelated when derived from a large pool of ferritin-haemosiderin as from a comparatively small pool of 'catabolic iron'. It therefore seemed that when iron was newly released from haemoglobin it was highly susceptible to desferrioxamine chelation.

It follows from this hypothesis that whenever haemoglobin catabolism is enhanced, increased amounts of iron should be available for chelation. Haemorrhage into soft tissue is a clinical condition in which haemoglobin catabolism is suddenly increased. This paper reports some serial observations in patients who had sustained major fractures and

Received for publication 28 February 1966 in whom it could be assumed that significaro haemorrhage had occurred into soft tissues, most at a known time. It shows that in the course 8 haemoglobin degradation, which occurs at the site of the haematoma, considerable amounts of iro become available for chelation by desferrioxaming in greater quantity than can be accounted for by tr: local increase in ferritin-haemosiderin.

\section{MATERIALS AND METHODS}

Chelation of body iron by desferrioxamine was estimatec by the differential ferrioxamine test (Fielding, 1965) Briefly, the procedure consists of an intravenous inje tion of a body-weight dose of desferrioxamine methane sulphonate (Desferal, Ciba), together with a bod? weight dose of ferrioxamine labelled with $2 \mu \mathrm{c}$. ${ }^{59} \mathrm{Fe}$. . single six-hour specimen of urine is collected. The tota amount of ferrioxamine excreted is estimated chemically (Fielding and Brunström, 1964) and the proportion of the intravenous dose of ferrioxamine excreted in six hours is estimated as ${ }^{50} \mathrm{Fe}$ by standard methods. The urinaty ferrioxamine is derived partly from the intravenous dose and partly from body iron chelated by desferrioxamine The amount of body iron chelated (Fv) is calculated as previously described and is expressed as micrograns ferrioxamine per kilogram body weight. It may be noteg here that in terms of the observations made the expres sion becomes:

Fv $(\mu \mathrm{g} . / \mathrm{kg})=$. body iron chelated, as ferrioxamine

$=\left[\right.$ Ferrioxamine in urine $\times{ }^{59} \mathrm{Fe}$ activity of

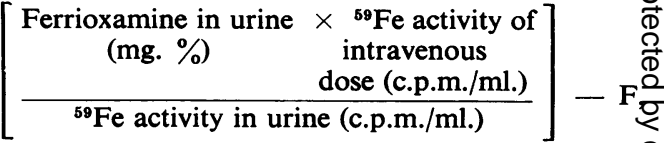

where $\mathrm{F}=$ Ferrioxamine in test dose (mg. \%) 
In this procedure, a considerable proportion of the small dose of ${ }^{59} \mathrm{Fe}$ is excreted in the urine; the test may therefore be repeated many times without significant exposure to radiation.

Serum iron was estimated by the method of Kok and Wild (1960).

Total iron-binding capacity (T.I.B.C.) was measured by the absorption of excess ferric chloride with magnesium carbonate (Ramsay, 1957).

CLINICAL MATERIal Five patients who had sustained fractures were investigated as soon as practicable after injury and at intervals thereafter: the relevant clinical data are summarized in the Table. The timing of investigations could not follow a predetermined schedule because of clinical considerations. Three patients, cases 113, 126, and 250 , suffered major fractures and haemorrhage at the site was assessed as considerable; case 143 proved to have a pathological fracture due to secondary malignant invasion; case 134 was a fracture of pelvis without displacement, and probably without major local haemorrhage. Repeated observations were made after injury for varying periods of time up to 138 days: these included desferrioxamine chelation, serum iron, total iron-binding capacity, haemoglobin, and haematocrit. In only one case could the first estimation be made on the same day as the injury; in three cases the first estimations were made the day after injury; and in one case it was made on the second day after injury. No haematinic therapy was given during these observations.

\section{RESULTS}

SERUM IRON In three of the four patients examined within 24 hours of injury, markedly low serum iron levels were found. In the fifth patient (case 134), examined for the first time on the second day, serum iron was also very low. In two cases, low values persisted for as long as 21 and 40 days, although this could not be ascribed to the initial injury alone, since operative intervention was undertaken in the interval (see Table).

TOTAL IRON-BINDING CAPACITY In four of the five patients, low serum iron-binding capacities were also observed, and these low values also tended to persist for periods up to $\mathbf{4 0}$ days (see Table).

CHELATION OF BODY IRON BY DESFERRIOXAMINE The results in four patients in whom initial observations were made either on the same day or on the day after injury are shown in Figure 1. The first estimations gave $\mathrm{Fv}$ values at the lower end of the range for normal men. In one woman patient, case 126 , an initial Fv, $83 \mu \mathrm{g} . / \mathrm{kg}$., indicated depletion of body iron stores (Fielding, O'Shaughnessy, and Brunström, 1965).

At the second test, which was carried out at varying intervals from the second to the sixth day
TABLE

SUMMARY OF CASES STUDIED

\begin{tabular}{|c|c|c|c|c|}
\hline Clinical & $\begin{array}{l}\text { Days } \\
\text { after } \\
\text { Injury }\end{array}$ & $\begin{array}{l}H b \\
(g . p e r \\
100 \mathrm{ml} .)\end{array}$ & $\begin{array}{l}\text { Serum } \\
\text { Fe/T.I.B.C. } \\
(\mu g . \text { per } \\
100 \mathrm{ml} .)\end{array}$ & $\begin{array}{l}F v \\
(\mu g . / k g .)\end{array}$ \\
\hline \multirow{8}{*}{$\begin{array}{l}\text { Case } 113 \\
\text { Male, age } 19 \\
\text { Fracture shaft right } \\
\text { femur; operation, } \\
\text { 7th day, intramedullary } \\
\text { nail }\end{array}$} & 0 & 16.0 & - & - \\
\hline & 1 & $15 \cdot 4$ & $24 / 237$ & 188 \\
\hline & 3 & - & - & 689 \\
\hline & 6 & $14 \cdot 1$ & $98 /-$ & 1,540 \\
\hline & 9 & $13 \cdot 4$ & $30 / 153$ & 783 \\
\hline & 12 & $12 \cdot 8$ & $15 / 180$ & 2,629 \\
\hline & 19 & - & $40 / 240$ & 813 \\
\hline & 40 & $14 \cdot 7$ & $46 / 174$ & 282 \\
\hline \multirow{6}{*}{$\begin{array}{l}\text { Case } 126 \\
\text { Female, age } 54 \\
\text { Compound fracture } \\
\text { tibia; operation, 12th } \\
\text { day, intramedullary } \\
\text { nail }\end{array}$} & 1 & $12 \cdot 2$ & $43 / 225$ & 83 \\
\hline & 5 & $11 \cdot 5$ & $55 / 164$ & 545 \\
\hline & 8 & $11 \cdot 5$ & $44 / 222$ & 870 \\
\hline & 14 & $11 \cdot 8$ & $18 / 258$ & 1,030 \\
\hline & 21 & $12 \cdot 8$ & $46 / 210$ & 725 \\
\hline & 47 & $13 \cdot 1$ & $85 / 337$ & 266 \\
\hline $\begin{array}{l}\text { Transfused } 2 \text { units on } \\
\text { day of injury }\end{array}$ & 138 & $13 \cdot 1$ & $116 / 378$ & 160 \\
\hline \multirow{3}{*}{$\begin{array}{l}\text { Case } 134 \\
\text { Male, aged } 32 \\
\text { Fracture pelvis, no } \\
\text { displacement }\end{array}$} & 2 & $13 \cdot 8$ & $19 / 240$ & 651 \\
\hline & 5 & $14 \cdot 1$ & $48 / 252$ & 259 \\
\hline & 8 & - & $70 / 258$ & 360 \\
\hline \multirow{4}{*}{$\begin{array}{l}\text { Case } 143 \\
\text { Female, age } 61 \\
\text { Pathological fracture } \\
\text { head of femur; pinned } \\
\text { 2nd day } \\
\text { Died, 36th day }\end{array}$} & 1 & $13 \cdot 8$ & $79 / 218$ & 226 \\
\hline & 5 & $10 \cdot 6$ & $52 / 162$ & 680 \\
\hline & 14 & $12 \cdot 8$ & - & - \\
\hline & 27 & $14 \cdot 1$ & $25 / 75$ & 617 \\
\hline \multirow{6}{*}{$\begin{array}{l}\text { Case } 250 \\
\text { Male, aged } 41 \\
\text { Fracture tibia; } \\
\text { operation, } 11 \text { th day, } \\
\text { plating }\end{array}$} & 0 & $13 \cdot 4$ & $47 / 354$ & 182 \\
\hline & 6 & $13 \cdot 1$ & $63 / 342$ & 576 \\
\hline & 13 & $13 \cdot 1$ & $94 / 396$ & 708 \\
\hline & 20 & 13.8 & $108 / 320$ & 442 \\
\hline & 26 & $12 \cdot 8$ & $62 /-$ & 1,699 \\
\hline & 33 & $12 \cdot 2$ & $76 /-$ & 641 \\
\hline
\end{tabular}

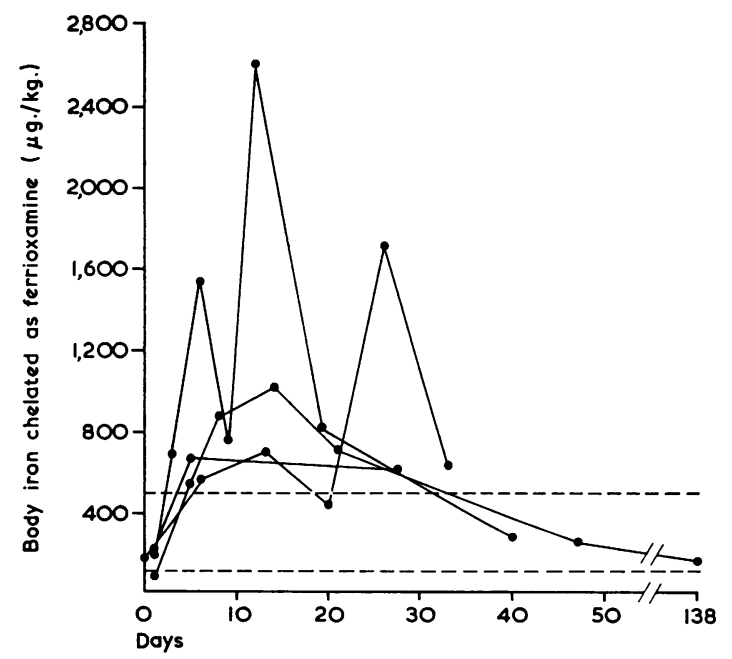

FIG. 1. Serial tests for desferrioxamine chelation of body iron as ferrioxamine ( $F v)$, after fracture in four patients. The horizontal interrupted lines show the range in normal men. 


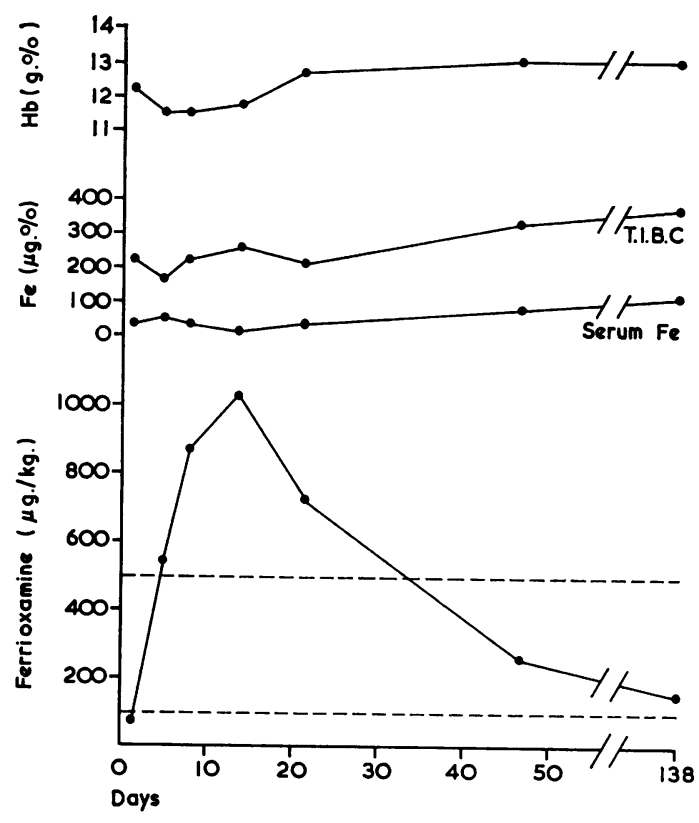

FIG. 2. Female age 54. Compound fracture of tibia (case 126). Serial tests of desferrioxamine chelation, serum $\mathrm{Fe}$, T.I.B.C. and haemoglobin. The interrupted lines show the range in normal men.

after injury, a marked increase in chelation values was found. All were above the range for normal men and this applied also to case 134 in which the first observation was made on the second day after injury. The high values for body iron mobilized by desferrioxamine persisted or increased for periods of time between 21 and 33 days of observation. The maximum values observed in each case were 2,629, $1,030,651,680$, and $1,699 \mu \mathrm{g} . / \mathrm{kg}$. In three cases, chelation values were seen to return to the normal range within five, 40 , and 47 days. The early return at five days to normal values in case 134 (see Table, not shown on graph) was associated with a fracture of the pelvis without displacement, and presumably without major haemorrhage at the site.

The time relationship between chelation value, haemoglobin, serum iron, and iron-binding capacity is shown for one case in Figure 2. Although no data are available before injury, comparison of the levels finally achieved illustrate the markedly depressed values for serum iron and total iron-binding capacity observed soon after injury. It is also notable that the spontaneous recovery of post-traumatic anaemia coincided with the presence of increased amounts of mobilizable iron as measured by desferrioxamine chelation. During this period of recovery, the serum iron fell as low as $18 \mu \mathrm{g}$. per $100 \mathrm{ml}$.

\section{DISCUSSION}

SERUM IRON AND T.I.B.C. There have been few studies of the effects of trauma on iron metabolism Feldthusen, Larsen, and Lassen (1953) showed thaf serum iron fell after major surgery and remained low for 12 days' observation. These observations were extended to include other forms of stress, including fractures and coronary occlusion (Feld $\frac{O}{0}$ thusen and Lassen, 1954), when it was shown thates serum iron values were normal at four and 12 hourso after stress, but were markedly reduced by 24 hours Nylander (1955) also studied long-bone fractures్ and found that serum transferrin was reduced as welth as serum iron. On the day of injury, T.I.B.C. values were normal, but fell regularly by 24 hours. He suggested that these effects were part of the adrenocortical response to stress, operating through reticulo endothelial function. Baird and Podmore (1965) alsoo showed that after major surgery serum iron fell within six hours; plasma iron turnover was reduced.c

The present findings agree with these previous observations on the effect of injury on serum iron and total iron-binding capacity. The low values wereg seen to persist for as long as six weeks where surgical intervention was undertaken. It is perhaps not widelyo known that this phenomenon seriously limits thes value of serum iron and T.I.B.C. estimations in the diagnosis of anaemias in surgical patients. They cer응 tainly add no weight to the differentiation of the anaemias of iron deficiency, infection, malignancy, or renal failure, and may be misleading.

It has been suggested that transferrin-bound iron is the immediate source of iron chelated by desferrioxamine, since serum iron is usually raised im conditions such as haemochromatosis, which give high chelation values. In support of this, Wohlen. (1962) showed that transferrin may be deprived of its. bound iron by desferrioxamine in vitro, although Ventura (1964) and Hallberg and Hedenberg (1965) b brought evidence to show that it does not occur in vivo to any measurable extent. The association of greatly increased body-iron chelation by desfer rioxamine in the presence of low serum iron values in the cases reported here, suggests that transferrin- $N$ bound iron is not a significant source or an intert mediary in the mobilization of body iron by des ferrioxamine.

BODY-IRON CHELATION AFTER FRACTURE WhenD measured within 24 hours after a major fracture and therefore after a presumed soft-tissue haemorrhage 0 the amount of iron mobilized by desferrioxamine? was found to be normal in three patients and in the्? iron-deficiency range in one. From the second das after injury, greatly increased amounts of body irong became available for mobilization by the chelating 
agent. The amounts of iron mobilized exclude the possibility that this increase derives from normal storage sites. It is reasonable therefore to assume that the site from which this increased mobilization of iron occurs is in the soft-tissue haematoma associated with fractures where rapid degradation of haemoglobin is in process. It is of course obvious that some increase in mobilizable iron would occur at the site, since ferritin and haemosiderin are being formed and thus are adding to the total amount of 'storage iron'. But the quantitative features of the results show that this could make only a minor contribution to the increases observed. If it is assumed that as much as 1 litre of blood is shed at the site of the fracture and all the haemoglobin iron is transformed at one time, this would provide about $500 \mathrm{mg}$. iron as ferritin-haemosiderin. This is to be compared with the findings in haemochromatosis (Fielding, O'Shaughnessy, and Brunström, 1966) in which iron stores, 40 to 80 times as great, give rise to chelation values of about the same order. The increase in ferritin and haemosiderin at the site of the haematoma can therefore account for only a small part of the increase in desferrioxamine-mobilizable iron observed. Since haemoglobin iron itself is not chelatable by desferrioxamine, these results offer additional evidence for the presence of a readily chelatable form of iron in the course of haemoglobin catabolism.

The variable anatomical disposition, the amounts and timing of interstitial haemorrhage after fractures, and the subsequent intervention of surgery, preclude the possibility of observing an exactly reproducible pattern of chelation values in each case. However, in the group as a whole, it may be seen that mobilizable iron increases towards a maximum between 10 and 20 days and may not return to normal levels until more than 30 days. It is of interest to relate this pattern of varying chelatibility to the events occurring in a haematoma in soft tissue. A classical description of these events was given by Niven (1935) and by Muir and Niven (1935), who studied red cell phagocytosis in tissue culture and in experimental subcutaneous haematomas in the mouse, rat, and rabbit. Haemolysis of free interstitial red cells seems to play only a minor part in their disposal. Phagocytosis by proliferating histiocytes proceeds at a rapidly increasing rate and is described as remarkable by 48 hours. Phagocytosis continues as long as red cells remain free and at eight days it is as active as at earlier stages. Free haemoglobin is to be seen in the haematoma until the fifteenth day. In individual phagocytes, the amount of prussian blue-reacting iron increases from the first faint diffuse reaction within hours after haematoma formation, until fine and coarse granules of haemosiderin appear. In the haematoma as a whole, the amount of haemosiderin (and of 'haematoidin') gradually increases and 'large amounts' are present when the observations were discontinued at 36 days in the mouse and 43 days in the rat. In relating these events to the amount of iron available for chelation at varying times after injury, it may be seen, first, that chelation values are already above the normal range on the second day, when only a small proportion of total haemoglobin iron in the haematoma could be transformed to haemosiderin; second, that chelation increases to about the time when free haemoglobin may still be recognized in the haematoma; and third, that when chelation decreases, large amounts of haemosiderin are still at the site. These considerations also suggest that ferritinhaemosiderin is not the source of the high chelation activity.

This investigation provides further evidence for the view that during the catabolism of haemoglobin, iron is released from its porphyrin linkage in a physico-chemical form which is highly susceptible to chelation by desferrioxamine. The chelatability may be an expression of its chemical form or of its accessibility by the chelating agent, or both factors may operate.

It was previously suggested (Fielding, 1965) that if chelatability with desferrioxamine were paralleled by chelatability with physiological chelators such as transferrin, it becomes possible to understand how iron derived from the constant breakdown of haemoglobin is preferentially utilized for further haem synthesis, to the virtual exclusion of storage iron for this purpose. The coincidence in time of spontaneous recovery from post-traumatic anaemia, with the increasing amounts of desferrioxamine-chelatable iron, is suggestive of a parallelism between transferrin and desferrioxamine chelatibility.

We wish to thank Mr. A. J. Harrold, F.R.C.S., for cooperation in investigating patients in his care; the North West Metropolitan Regional Hospital Board for research grants; and Ciba Laboratories, Ltd., for gifts of drugs and apparatus. (Requests for reprints should be made to J. F.)

\section{REFERENCES}

Baird, I. M., and Podmore, D. A. (1965). In Proc. ann. gen. Meet. Brit. Soc. Haemat., abstr., p. 34.

Feldthusen, U., Larsen, V., and Lassen, N. A. (1953). Acta med. scand., 147, 311.

—

Fielding, J. (1965). J. clin. Path., 18, 88. , and Brunström, G. M. (1964). Ibid., 17, 395.

- O'Shaughnessy, M. C., and Brunström, G. M. (1965). Lancet, 2, 9. ,--1 (1966). J. clin. Path., 19, 159.

Hallberg, L., and Hedenberg, L. (1965). Scand. J. Haemat., 2, 67.

Kok, D. A. and Wild, F. (1960). J. clin. Path., 13, 241.

Muir, R. and Niven, J. S. F. (1935). J. Path. Bact., 41, 183.

Niven, J. S. F. (1935). Ibid., 41, 177.

Nylander, G. (1955). Acta endocr. (Kbh.), 20, 148.

Ramsay, W. N. M. (1957). Clin. chim. Acta, 2, 221.

Ventura, S. (1964). In Iron Metabolism, edited by F. Gross, p. 597.

Wohler, F. (1962). Schweitz. med. Wschr., 92, 1295. 